\title{
A new statistical approach to improve the satellite-based estimation of the radiative forcing by aerosol-cloud interactions
}

\author{
Piyushkumar N. Patel ${ }^{1}$, Johannes Quaas ${ }^{2}$, and Raj Kumar ${ }^{1}$ \\ ${ }^{1}$ Space Applications Centre, ISRO, Ahmedabad, India \\ ${ }^{2}$ Institute for Meteorology, Universität Leipzig, Leipzig, Germany \\ Correspondence to: Piyushkumar N. Patel (piyushether@gmail.com)
}

Received: 27 July 2016 - Discussion started: 7 September 2016

Revised: 13 February 2017 - Accepted: 13 February 2017 - Published: 16 March 2017

\begin{abstract}
In a previous study of Quaas et al. (2008) the radiative forcing by anthropogenic aerosol due to aerosol-cloud interactions, $\mathrm{RF}_{\mathrm{aci}}$, was obtained by a statistical analysis of satellite retrievals using a multilinear regression. Here we employ a new statistical approach to obtain the fitting parameters, determined using a nonlinear least square statistical approach for the relationship between planetary albedo and cloud properties and, further, for the relationship between cloud properties and aerosol optical depth. In order to verify the performance, the results from both statistical approaches (previous and present) were compared to the results from radiative transfer simulations over three regions for different seasons. We find that the results of the new statistical approach agree well with the simulated results both over land and ocean. The new statistical approach increases the correlation by $21-23 \%$ and reduces the error compared to the previous approach.
\end{abstract}

\section{Introduction}

Aerosols are considered to have a large effect on climate, both through aerosol-radiation interactions and aerosolcloud interactions, by serving as cloud condensation nuclei $(\mathrm{CCN})$, therefore increasing $N_{\mathrm{d}}$ and thus cloud albedo (Twomey, 1974), as well as rapid cloud adjustments (Boucher et al., 2013). Much work has been done to quantify the radiative forcing by aerosol-cloud interaction $\left(\mathrm{RF}_{\mathrm{aci}}\right)$, yet it remains highly uncertain. The annual radiative forcing from aerosol induced changes in cloud albedo were reported as $-0.7 \mathrm{Wm}^{-2}$ with an uncertainty range of -1.8 to $-0.3 \mathrm{Wm}^{-2}$ (Boucher et al., 2013); this effect could offset much of the warming from greenhouse gases (Huber and Knutti, 2011), emphasising the need to understand the effect so that we can better predict the future climate.

In this study, we concentrate on the $\mathrm{RF}_{\mathrm{aci}}$, the change in cloud albedo with increasing aerosol. An increasing aerosol at constant cloud water content is supposed to decrease droplet size, which in turn increases the cloud albedo due to the increased scattering of the smaller, more numerous cloud droplets. Feingold et al. $(2001,2003)$ and McComiskey et al. (2009) proposed a metric to quantify the microphysical component of the cloud albedo effect $(\mathrm{ACI}=$ $-d \ln N_{\mathrm{d}} / d \ln \alpha$ ), where $N_{\mathrm{d}}$ is the cloud droplet number concentration and $\alpha$ is a proxy for the aerosol burden. A variety of proxies has been used to represent the cloud response to the change in aerosol, e.g. cloud optical depth $\left(\tau_{\mathrm{c}}\right)$, cloud drop number concentration $\left(N_{\mathrm{d}}\right)$ and cloud droplet effective radius $\left(r_{\mathrm{e}}\right)$. Similarly, various proxies have been used to represent the total ambient aerosol burden, including aerosol number concentration $\left(N_{\mathrm{a}}\right)$, aerosol optical depth $\left(\tau_{\mathrm{a}}\right)$ and aerosol index $(\mathrm{AI})$. An overview of published relationships and their biases due to mismatches between process and analysis scales are discussed in McComiskey and Feingold (2012). Values for aerosol-cloud interaction (ACI) metrics from observations often differ significantly from model-based values (Quaas et al., 2008, 2009; Bellouin et al., 2008; Penner et al., 2011, 2012). For example, the observationally based values of $\mathrm{RF}_{\mathrm{aci}}$, often in the range of -0.2 to $-0.6 \mathrm{Wm}^{-2}$ (Quaas et al., 2008; Bellouin et al.,2013), tend to be weaker than the modelled values in the range of -0.5 to $-1.9 \mathrm{Wm}^{-2}$ (IPCC, 2007). The differences in model and observationally based $\mathrm{RF}_{\mathrm{aci}}$ have to be reconciled. Penner et al. (2011) reported that the lower sensitiv- 
ities of cloud droplet number concentration, when considering aerosol optical depth (AOD) compared to aerosol index as aerosol quantity may lead to a significant underestimation in satellite-based $\mathrm{RF}_{\text {aci }}$. However, Quaas et al. (2011) pointed out the weaknesses in the approach used by Penner et al. (2011). Clearly, further study is needed to reduce the uncertainties in both observationally and model-based estimates of aerosol $\mathrm{RF}_{\mathrm{aci}}$ and to reconcile the differences.

Quaas et al. (2008) derived the anthropogenic aerosol $\mathrm{RF}_{\mathrm{aci}}$ based on satellite retrievals of aerosol and clouds properties using statistical relationships between cloud properties and anthropogenic aerosols without the use of a radiative transfer model. They developed a statistical relationship between planetary albedo and cloud properties using a multilinear fit and, further, between the relationships of cloud properties and aerosol optical depth. Quaas et al. (2008) suggested that uncertainties in the statistical relationship and fitting parameters introduced uncertainty in the estimate of $\mathrm{RF}_{\mathrm{aci}}$. Therefore, it is useful to reassess the estimated $\mathrm{RF}_{\mathrm{aci}}$ by using a new statistical fitting approach. The main objective of this study is to explore the uncertainty in the satellitebased quantification of $\mathrm{RF}_{\mathrm{aci}}$. This study differs from previous studies by introducing a new statistical fitting approach to obtain the fitting parameters for the estimates of $\mathrm{RF}_{\mathrm{aci}}$, determined using a nonlinear fit between planetary albedo and cloud properties. To verify the present approach, the results from both statistical approaches are compared with the results from a radiative transfer model.

The rapid socio-economic development in the recent past has increased the anthropogenic emissions in the south Asian region along with several parts of the world. South Asia and its territories are among the potential sources of a variety of aerosol species (both natural and anthropogenic), and extensive investigations have been made in the past years (e.g. Chin et al., 2000; Di Girolamo et al., 2004; Moorthy et al., 2013). These densely populated regions with increasing power demand, fuel consumption and equally diverse geographical features are also vulnerable to the impacts of atmospheric aerosols to the climate (e.g. Liu et al., 2009). The complex geography of this region contributes significant amounts of natural aerosols (desert dust, pollen, sea salt, etc.) to the atmosphere, which mix with anthropogenic ones, making the aerosol environment one of the most complex in the world (Moorthy et al., 2015). The large spatial heterogeneity of the sources coupled with the atmospheric dynamics driven by topography and contrasting monsoons make south Asia's aerosols very difficult to characterise, and it is also difficult to model their implications for radiative and climate forcing. While tropospheric perturbations would produce strong regional signatures, their global impacts still remain marginally above the uncertainty levels (IPCC, 2013). In recent years, several studies are carried out on the aerosol characterisation and its direct effect over south Asia, but there have been very few studies reported on the aerosol indirect effect using ground- and satellite-based measurements due to com-

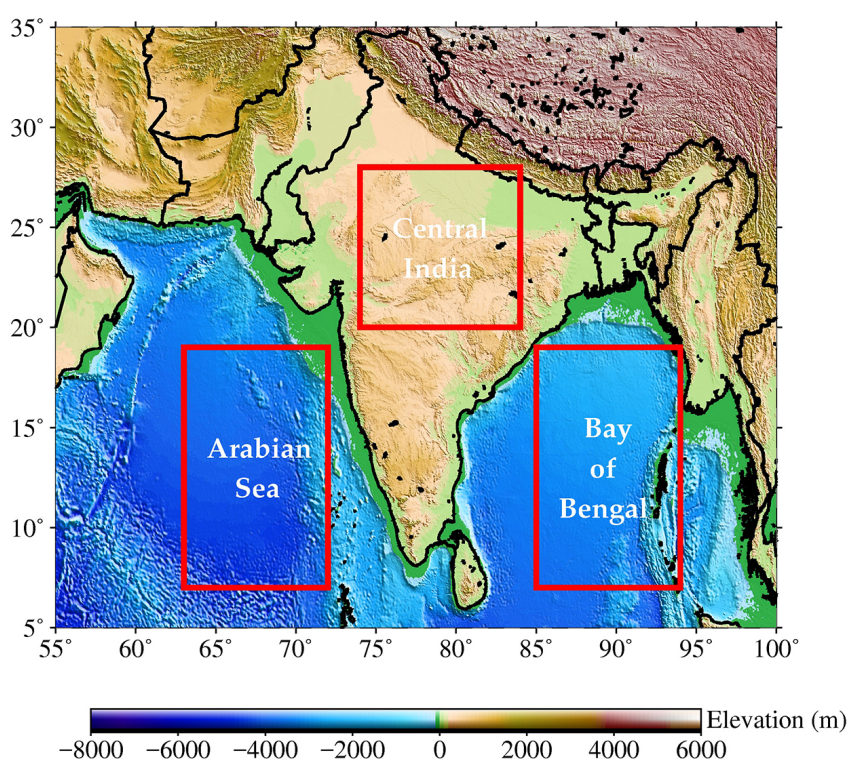

Figure 1. Map of India and surroundings showing the study regions. The regions covered by red box represent the study locations (Arabian Sea, Bay of Bengal and Central India).

plex aerosol and cloud environments. Therefore, we discuss the $\mathrm{RF}_{\mathrm{aci}}$ for both the anthropogenic and natural fraction of aerosol for a period of 6 years (2008-2013) for three different regions of south Asia (Fig. 1; Arabian Sea (AS; $63-72^{\circ}$ E, $7-$ $19^{\circ} \mathrm{N}$ ), Bay of Bengal (BOB; 85-94 ${ }^{\circ} \mathrm{E}, 7-19^{\circ} \mathrm{N}$ ) and Central India $\left(\mathrm{CI} ; 75-84^{\circ} \mathrm{E}, 20-30^{\circ} \mathrm{N}\right)$ ), having significantly distinct aerosol environments as a result of variations in aerosol sources and transport pathways (Cherian et al., 2013; Das et al., 2015; Tiwari et al., 2015). Additionally, we also discuss the uncertainties of the results in the following sections.

\section{Data}

We combine measurements of aerosol, cloud and radiative properties to derive the top of the atmosphere (TOA) $\mathrm{RF}_{\mathrm{aci}}$ for both anthropogenic and natural aerosols. Data acquired by MODerate Resolution Imaging Spectroradiometer (MODIS) and Clouds and the Earth's Radiant Energy System (CERES) mounted on Aqua (Parkinson, 2003) and the Ozone Monitoring Instrument (OMI) onboard Aura (Schoeberl et al., 2006) are used in this study. We use the broadband shortwave planetary albedo $(\alpha)$ (Wielicki et al., 1996; Loeb, 2004; Loeb et al., 2007) as retrieved by CERES in combination with cloud properties from MODIS (Minnis et al., 2003) and $\operatorname{AOD}\left(\tau_{\mathrm{a}}\right)$ and fine-mode fraction (FMF) as retrieved by MODIS onboard Aqua (Remer et al., 2005). Albedo and cloud properties are from the CERES single-scanner footprint (SSF) Level-2 Edition-3A data set at a $20 \times 20 \mathrm{~km}^{2}$ horizontal resolution, and aerosol properties (AOD and FMF) at $550 \mathrm{~nm}$ from the MYD04 level-2 collection-5.1 data set at a $10 \times 10 \mathrm{~km}^{2}$ horizontal resolution are used. We used 
the UV aerosol index (UV-AI; Torres et al., 1998) measured by OMI-Aura (Levelt et al., 2006) from the OMAERUVG level-2 version 003 data set at $0.25^{\circ} \times 0.25^{\circ}$ grid, which is a gridded data set containing retrievals from the OMAERUV (Torres et al., 2007) algorithm. The data from CERES and MODIS level-2 products are interpolated to a $0.25^{\circ} \times 0.25^{\circ}$ regular longitude-latitude grid to separate the aerosol and cloud properties for anthropogenic and natural aerosols using UV-AI. Daily data, taken at roughly 13:30 LT, cover the 2008-2013 period.

\section{Methods}

All statistics between aerosol and cloud properties are computed separately for three regions and for each month of data at a $0.25^{\circ} \times 0.25^{\circ}$ grid resolution. To avoid the greater uncertainty that is inherent in distinguishing clearly between aerosols and clouds and the accurate retrieval of cloud properties, only single-layer clouds with a liquid water path (LWP) $>20 \mathrm{~g} \mathrm{~m}^{-2}$ are taken into account. $\mathrm{RF}_{\text {aci }}$ for anthropogenic and natural aerosols are calculated using the methods outlined by Quaas et al. (2008) with the new statistical approach. As a part of this process, the method by Kim et al. (2007), the MODIS-OMI algorithm (MOA), is employed to classify the aerosol types into one of four types: sea salt, carbonaceous, dust and sulfate; this is done using MODIS FMF and OMI UV-AI data. FMF provides information on the representative size of the aerosol. FMF is close to 1 for mostly small aerosol particles, which implies an anthropogenic origin, and FMF becomes small for nonanthropogenic aerosol like dust. UV-AI allows us to detect the absorption due to the presence of an aerosol layer by utilising the sensitivity of absorptive aerosol in UV. Under most conditions, UV-AI is positive for absorbing aerosols and negative for non-absorbing aerosols. Using these two independent data sets, aerosol can be classified. Details for the aerosol classification are discussed in Kim et al. (2007). For the purpose of this research, the combination of dust and seasalt AOD considered as a natural AOD and an anthropogenic AOD contains the combination of carbonaceous and sulfate. Further, the $\mathrm{RF}_{\mathrm{aci}}$ is estimated for both anthropogenic and natural aerosols.

\subsection{Satellite-based estimate of $\mathbf{R F}_{\mathbf{a c i}}$}

$\mathrm{RF}_{\mathrm{aci}}$ is a function of the relationship between AOD and $N_{\mathrm{d}}$ in a cloud. $N_{\mathrm{d}}$ is not directly provided by a satellite product and must be computed using cloud optical thickness $\left(\tau_{\mathrm{c}}\right)$ and effective droplet radius $\left(r_{\mathrm{e}}\right)$ for liquid water clouds assuming adiabaticity (Brenguier et al., 2000; Schüller et al., 2005; Quaas et al., 2006; Bennartz, 2007; Rausch et al., 2010).

$N_{\mathrm{d}}=\gamma \tau_{\mathrm{c}}^{1 / 2} r_{\mathrm{e}}^{-5 / 2}$

a constant value of $\gamma=1.37 \times 10^{-5} \mathrm{~m}^{-0.5}$ (Quaas et al., 2006) is used in this study. A limitation of this assumption is that it applies rather well to the stratiform clouds in the marine boundary layer but less so for convective clouds. A detailed explanation and uncertainty assessment are described in Bennartz (2007) and Rausch et al. (2010). Recently, Bennartz and Rausch (2017) showed that the uncertainties in the CDNC climatology from 13 years of Aqua-MODIS observations are in the order of $30 \%$ in the stratocumulus regions and 60 to $80 \%$ elsewhere, and CDNC's contribution to the total uncertainty for this study is discussed in the following section.

Quaas et al. (2008) have adopted the Loeb (2004) approach for the estimate of planetary albedo. Albedo $(\alpha)$ of a cloud scene can be well described by a sigmoidal fit as

$\alpha \approx(1-f)\left[\alpha_{1}+\alpha_{2} \ln \tau_{\mathrm{a}}\right]+f\left[\alpha_{3}+\alpha_{4}\left(f \tau_{\mathrm{c}}\right)^{\alpha_{5}}\right]^{\alpha_{6}}$,

where $\alpha_{1}-\alpha_{6}$ are fitting parameters obtained by a multilinear regression, where $\alpha_{5}$ is set as 1 (Ma et al., 2014). Dependency of $\tau_{\mathrm{a}}$ is introduced to include the clear part of the scene in the above equation, and $f$ is the cloud fraction. The satellite-based estimate of $\mathrm{RF}_{\mathrm{aci}}$ for anthropogenic and natural aerosols can be expressed as

$$
\begin{aligned}
\Delta F_{\text {ant } / \text { nat }}^{R F_{\text {aci }}}= & f_{\text {liq }} A\left(f, \tau_{\mathrm{c}}\right) \frac{1}{3} \frac{d \ln N_{\mathrm{d}}}{d \ln \tau_{\mathrm{a}}} \\
& {\left[\ln \tau_{\mathrm{a}}-\ln \left(\tau_{\mathrm{a}}-\tau_{\mathrm{a}}^{\mathrm{ant} / \mathrm{nat}}\right)\right] S, }
\end{aligned}
$$

where $A\left(f, \tau_{\mathrm{c}}\right)=\alpha_{4} \alpha_{5} \alpha_{6}\left[\alpha_{3}+\alpha_{4}\left(f \tau_{\mathrm{c}}\right)^{\alpha_{5}}\right]^{\alpha_{6}-1}\left(f \tau_{\mathrm{c}}\right)^{\alpha_{5}} d \ln$ $N_{\mathrm{d}} / d \ln \tau_{\mathrm{a}}$ is the sensitivity of cloud droplet number concentration $\left(N_{\mathrm{d}}\right)$ to a relative change in AOD. It is computed as the slope of the linear regression fit between the natural logarithm of $N_{\mathrm{d}}$ and AOD (Quaas et al., 2008). This value is calculated on a month-by-month basis and is unique to each region studied. $\tau_{\mathrm{a}}$ is the total $\mathrm{AOD}$, whereas $\tau_{\mathrm{a}}^{\mathrm{ant} / \text { nat }}$ are the anthropogenic and natural AOD derived from the FMF and UV-AI as estimated above. $A\left(f, \tau_{\mathrm{c}}\right)$ is the empirical function relating albedo to $f$ and $\tau_{\mathrm{c}} . S$ is the daily mean solar incoming solar radiation. $\mathrm{RF}_{\mathrm{aci}}$ is calculated separately for the anthropogenic and natural aerosols for all three regions for each month.

A goal of the present study is to assess the uncertainty in the satellite-based estimate of the $\mathrm{RF}_{\mathrm{aci}}$. For that purpose, we adopted the new statistical nonlinear least square fitting approach to obtain the six fitting parameters in Eq. (2). Nonlinear least square methods involve an iterative improvement to parameters values in order to minimise the residual sum of squares between the observed values and the predicated value of the dependent variables. We used the LevenbergMarquardt (L-M) algorithm (Levenberg, 1944) in the nonlinear least square approach to adjust the parameter values in the iterative procedure. This algorithm combines the GaussNewton method and the gradient descent method. In the gradient descent method, the sum of the squared errors is reduced by updating the parameters in the steepest descent direction. In the Gauss -Newton method, the sum of the 
squared errors is reduced by assuming the least squares function is locally quadratic and by finding the minimum of the quadratic. The L-M algorithm acts more like a gradient descent method when the parameters are far from the optimal value and acts more like the Gauss-Newton method when the parameters are close to their optimal value. More detail of this method is given in the literature (Levenberg, 1944; Transtrum et al., 2010; Transtrum and Sethna, 2012). In the present study, instead of considering $\alpha_{5}=1$ in the multiple regression, as in Quaas et al. (2008) and Ma et al. (2014), we obtained the values of all six fitting parameters using a nonlinear fitting approach (L-M algorithm) for each month and region. To get an impression of the performance of our statistical approach, we correlate $\alpha$ and $\mathrm{RF}_{\mathrm{aci}}$ at TOA obtained from both statistical fitting methods (multilinear and nonlinear) vs. $\alpha$ and $\mathrm{RF}_{\mathrm{aci}}$ simulated by a radiative transfer model for all three regions. The following section gives detailed information about the simulation of $\alpha$ and $\mathrm{RF}_{\text {aci }}$ using the radiative transfer model.

\subsection{Simulation of planetary albedo $(\alpha)$ and $\mathbf{R F}_{\text {aci }}$}

In order to verify both the statistical approaches, we performed a radiative transfer simulation to obtain $\alpha$ and $\mathrm{RF}_{\mathrm{aci}}$ for all three regions. Radiative transfer calculations are performed with the SBDART (Santa Barbara DISORT Atmospheric Radiative Transfer; Ricchiazzi et al., 1998), which is a plane-parallel radiative transfer code based on the DISORT algorithm for discrete-ordinate-method radiative transfer in multiple scattering and emitting layered media (Stamnes et al., 1988). The discrete ordinate method provides a numerically stable algorithm to solve the equations of plane-parallel radiative transfer in a vertically inhomogeneous atmosphere. Simulations are carried out for the solar spectrum $(0.2-$ $4.0 \mu \mathrm{m})$ for all three regions. Following the study by Quaas et al. (2008), Bellouin et al. (2013) performed a similar study with MACC reanalysis data, in which RT simulations, using a Monte Carlo method, were carried out to obtain the standard deviation for the uncertainty analysis. However, in the present study, $\mathrm{RF}_{\mathrm{aci}}$ is simulated using an $\mathrm{RT}$ model (SBDART) to validate the performance of both the statistical approaches used to compute the $\mathrm{RF}_{\text {aci }}$ using the statistical relationship between satellite measurements.

In the present study, simulations are carried out to simulate first $\alpha$ and later $\mathrm{RF}_{\mathrm{aci}}$ for the given inputs. Here $\alpha$ is evaluated as the ratio of broadband outgoing (or upwelling) shortwave flux to the incoming (or downwelling) solar flux. Inputs to the model include profiles of temperature and water vapour which are resolved into 32 layers extending from 1000 to 1 mbar and come from European Centre for Mediumrange Weather Forecast (ECMWF) reanalysis data. Table 1 shows the list of input parameters and their source provided to the RT model for the estimate of $\mathrm{RF}_{\mathrm{aci}}$. The total columnar amount of atmospheric ozone is provided from OMI-Aura. Surface albedo is set to 0.15 to represent a typical land cover
Table 1. The list of parameters and their sources used as an input to the SDBART model for the simulation of $\mathrm{RF}_{\mathrm{aci}}$.

\begin{tabular}{ll}
\hline Input parameters & Source \\
\hline $\begin{array}{l}\text { Temperature and water vapour } \\
\text { (for 32 layers extending from } \\
1000 \text { to } 1 \mathrm{hPa} \text { ) }\end{array}$ & ECMWF reanalysis \\
\hline Total columnar ozone & OMI-Aura \\
\hline Surface albedo & $\begin{array}{l}\text { For land - 0.15 } \\
\text { For ocean - default } \\
\text { value of "ocean" (given } \\
\text { in SBDART) }\end{array}$ \\
\hline Cloud effective droplet radius & $\begin{array}{l}\text { MODIS } \\
\text { retrievals reported in } \\
\text { CERES-SSF product }\end{array}$ \\
Cloud liquid water path & \\
Cloud fraction & $\begin{array}{l}\text { Computed from } \\
\text { data }\end{array}$ \\
\hline Geometrical thickness of cloud and ECMWF
\end{tabular}

value for $\mathrm{CI}$, and a predefined option for the ocean surface is used for the oceanic regions (AS and BOB). In the SBDART model, the cloud parameter inputs are effective droplet radius $\left(r_{\mathrm{e}}\right)$, liquid water path (LWP) and the cloud fraction, all of which are taken from MODIS retrievals reported in the CERES-SSF product. The geometrical thickness of cloud (CGT) is computed as the difference between cloud top and bottom heights. Cloud top height is taken from the CERESSSF product and cloud base height is evaluated using the geopotential height profile from ECMWF data. Only liquid water clouds are considered in the estimation of $\mathrm{RF}_{\mathrm{aci}}$. The upwelling and downwelling fluxes are computed individually for all three regions at satellite (MODIS-Aqua as a reference) overpass time.

The local radiative forcing associated with the $\mathrm{RF}_{\mathrm{aci}}$ is estimated as the difference between the perturbed and unperturbed radiative fluxes caused by perturbation in $N_{\mathrm{d}}$ due to the addition of aerosols while keeping the same meteorology. $\mathrm{RF}_{\mathrm{aci}}$ is diagnosed by making two calls to the radiative transfer code: the first call used the unperturbed satellite-derived $N_{\mathrm{d}}$ and the second used perturbed $N_{\mathrm{d}}$ due to anthropogenic and natural aerosols. The numerical evaluation of radiative flux for the perturbed case starts by determining the finite perturbation of cloud droplet number concentration $\left(\Delta N_{\mathrm{d}}\right)$, calculated as follows:

$$
\Delta N_{\mathrm{d}}^{\mathrm{ant} / \mathrm{nat}}=\frac{d \ln N_{\mathrm{d}}}{d \ln \tau_{\mathrm{a}}}\left[\ln \tau_{\mathrm{a}}-\ln \left(\tau_{\mathrm{a}}-\tau_{\mathrm{a}}^{\mathrm{ant} / \mathrm{nat}}\right)\right] .
$$

The finite perturbation in $N_{\mathrm{d}}$ is evaluated separately for anthropogenic and natural aerosol to estimate the radiative flux for the perturbed case. The perturbed value of $N_{\mathrm{d}}{ }^{\prime}\left(N_{\mathrm{d}}+\right.$ $\Delta N_{\mathrm{d}}$ ) is used to obtain a perturbed value of $r_{\mathrm{e}}$ using Eq. (5) 

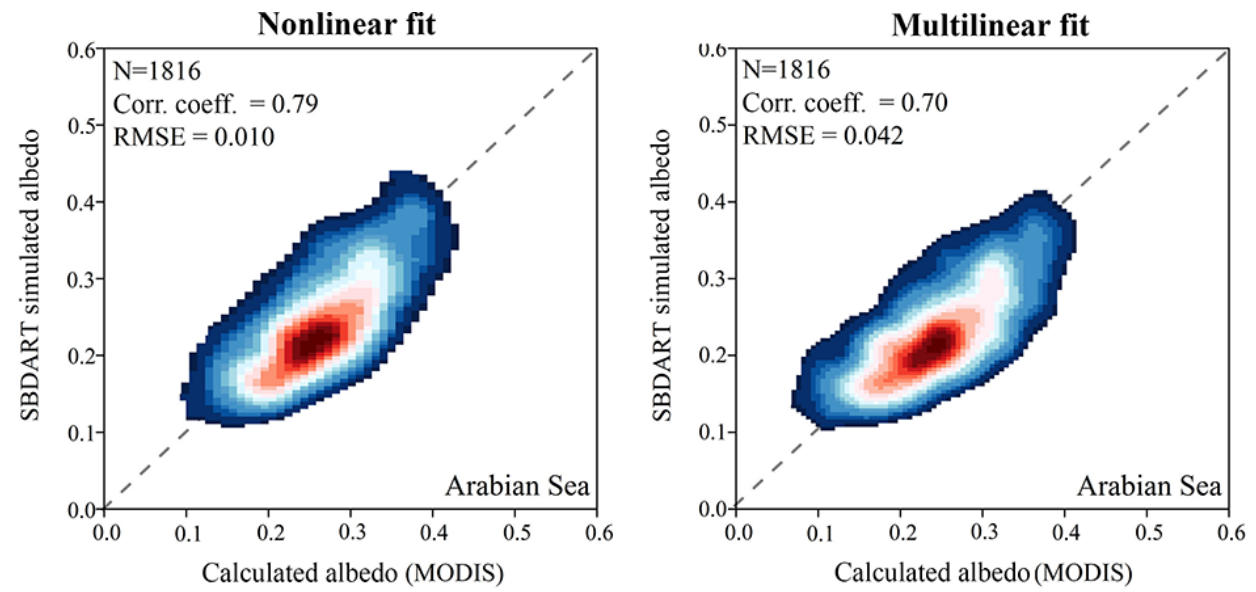

$\begin{array}{llllll}100 & 300 & 500 & 700 & 900 & 1100\end{array}$
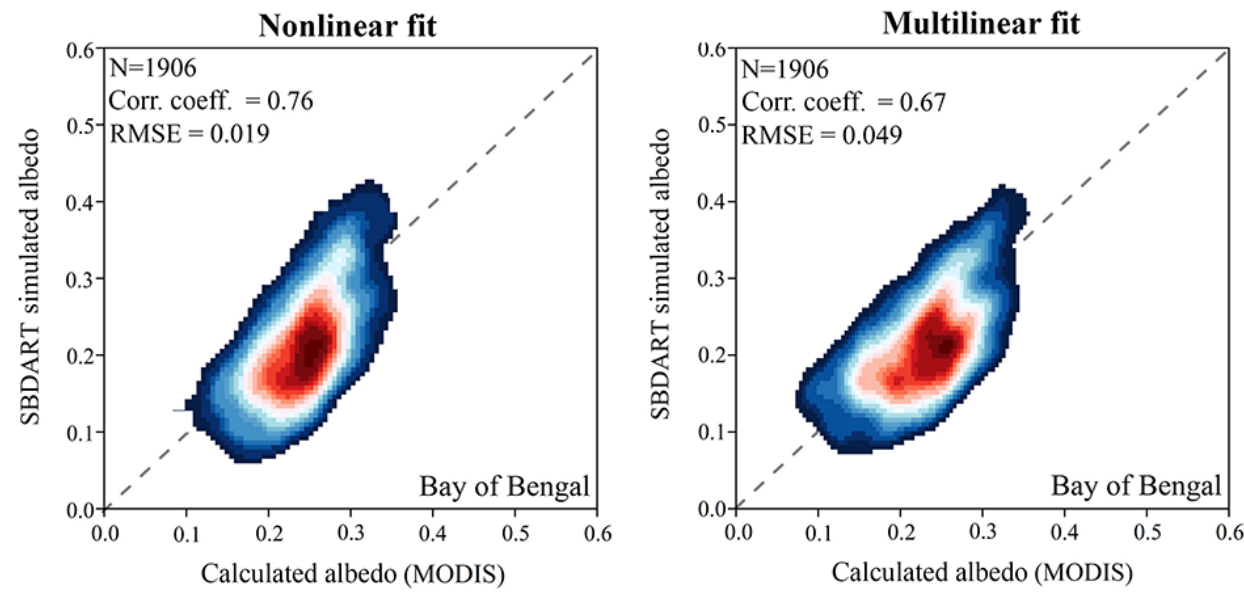

$\begin{array}{lllllll}100 & 250 & 400 & 550 & 700 & 850 & 1000\end{array}$
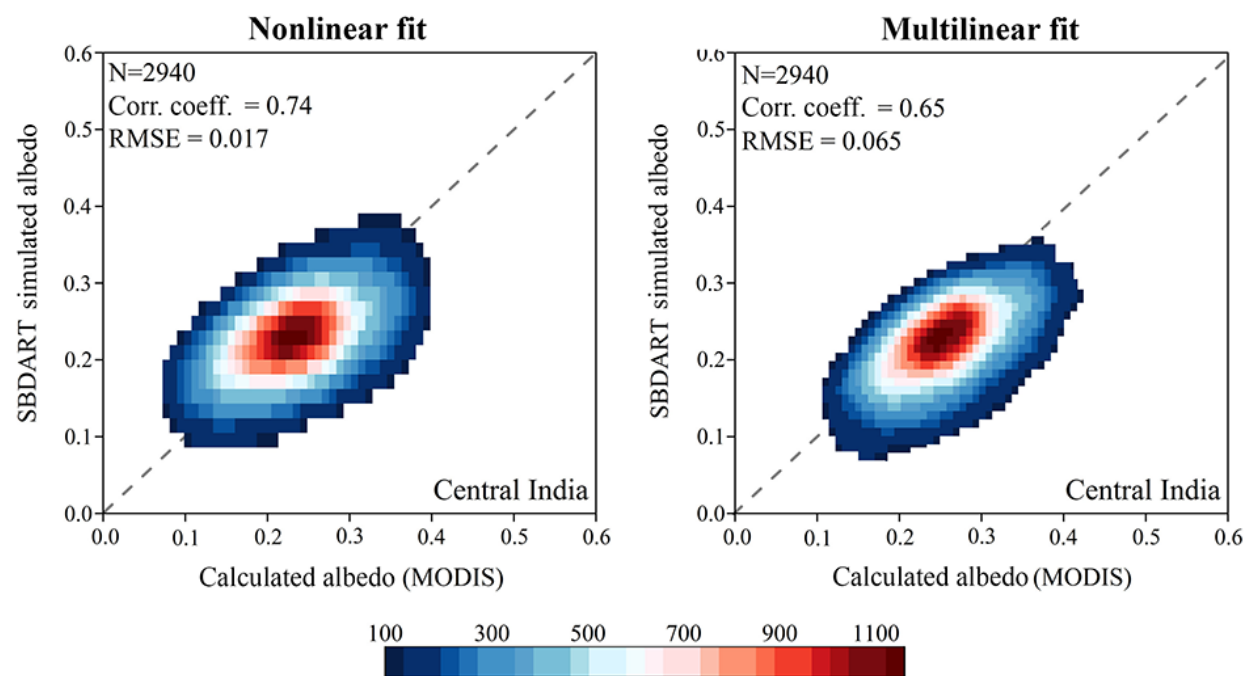

Figure 2. Scatter density plots of model-simulated albedo and albedo computed using both statistical fitting methods (nonlinear and multilinear fit) using satellite measurements for all three regions. 
for constant liquid water content because $r_{\mathrm{e}}$ is used as an input to the radiative transfer code.

$N_{\mathrm{d}}{ }^{\prime}=q_{1} /\left(\frac{4}{3} \pi r_{\mathrm{e}}^{3} \rho_{\mathrm{w}}\right)$,

where $\rho_{\mathrm{w}}$ is the liquid water density and $q_{1}$ the liquid water content ( $q_{1}=$ liquid water path/geometrical thickness). $\mathrm{RF}_{\mathrm{aci}}$ is diagnosed as $\mathrm{RF}_{\text {unperturbed }}-\mathrm{RF}_{\text {perturbed }}$ radiative fluxes at the top of the atmosphere because increased concentrations of aerosol reduce the effective radius of cloud particles, and smaller cloud particles reflect more radiation back to space. The following section describes the details of the regression analysis of $\alpha$ and $\mathrm{RF}_{\text {aci }}$ performed between values from statistical approaches and simulated values.

\section{Results}

\subsection{Regression analysis}

As stated in Sect. 3.1, the satellite-based estimates of $\mathrm{RF}_{\mathrm{aci}}$ are dependent on the fitting parameters $\alpha_{1}-\alpha_{6}$, obtained here from the two different statistical fitting approaches (multilinear and nonlinear). The parameters obtained from these two approaches are listed in Table S1 in the Supplement for all three regions investigated in this study. These parameters vary with months since we conducted both the fitting approaches for each month, but only the mean seasonal parameters are shown here. The main differences in fitting parameters from both methods are found in the values of $\alpha_{4}, \alpha_{5}$ and $\alpha_{6}$. The magnitude of the coefficients $\alpha_{4}$ and $\alpha_{6}$ is larger in the nonlinear fit than the multilinear regression fitting, which may reduce the magnitude of the coefficient $\alpha_{5}$. To accomplish the objective of this study, we correlate $\alpha$ and $\mathrm{RF}_{\text {aci }}$ at TOA obtained from both statistical fitting approaches (multilinear and nonlinear) with estimates obtained from the radiative transfer model for all three regions. Figure 2 shows scatter density plots of comparison between model-simulated albedo and the albedo computed from satellite measurements at a $0.25^{\circ} \times 0.25^{\circ}$ grid resolution using both statistical methods for all three regions. This regression analysis suggests that the albedo fitted by the new statistical approach (nonlinear fit) agrees well with the model-simulated albedo over both land and ocean. The scatter of the results from the nonlinear fit around the 1:1 line is much smaller compared to the multilinear fit, which is also reflected in the coefficients of determination $\left(R^{2}\right)$ ranging from 0.74 to 0.79 . However, a reduction in over- and underestimation at very large and very small albedos, respectively, is found in the nonlinear fit compared to the multilinear statistical approach. This is also clearly reflected in the values for the root mean square error (RMSE), which reduces from $0.042-0.065$ to $0.010-0.017$, supporting the expectation that the new statistical method is more reliable. Additionally, a comparison between the planetary albedo computed using both statistical fits and the CERES retrieved albedo is shown in Fig. S1 in the Supplement for all three regions. Similar to the results discussed above, the analysis shows good agreement between the CERES-derived albedo and the one calculated using the nonlinear fit.

In addition, we performed a comparison of $\mathrm{RF}_{\mathrm{aci}}$ obtained from satellite measurements using both statistical approaches with $R_{\text {aci }}$ simulated by SBDART for each season and for each region. Figure 3 illustrates the linear regression of $\mathrm{RF}_{\mathrm{aci}}$ from the two statistical approaches plotted against $\mathrm{RF}_{\mathrm{aci}}$ obtained from the radiative transfer model for both anthropogenic and natural aerosols for all seasons and all three regions. The analysis showed good statistical agreement with Pearson's correlation coefficient $r=0.82$ and 0.75 and $\mathrm{RMSE}=0.037$ and $0.042 \mathrm{Wm}^{-2}$ for the anthropogenic and natural fraction of aerosols, respectively. An examination of Fig. 3 reveals that the nonlinear fitting approach reduces the scatter seen for the multilinear fit and the improvement in correlation with the simulated forcing. The nonlinear fit increases the correlation by $21-23 \%$ and reduce the RMSE by $0.007-0.011 \mathrm{~W} \mathrm{~m}^{-2}$ compared to the multilinear approach. The relative difference between the RT-simulated and the statistically computed $\mathrm{RF}_{\mathrm{aci}}$ is computed for both the statistical methods. The mean relative difference in $\mathrm{RF}_{\mathrm{aci}}$ for the anthropogenic fraction of AOD is $0.021 \mathrm{~W} \mathrm{~m}^{-2}$ in the nonlinear and $0.033 \mathrm{~W} \mathrm{~m}^{-2}$ in the multilinear statistical approach, whereas for the $\mathrm{RF}_{\mathrm{aci}}$ of the natural fraction of $\mathrm{AOD}$, it is $0.032 \mathrm{~W} \mathrm{~m}^{-2}$ in the nonlinear and $0.053 \mathrm{~W} \mathrm{~m}^{-2}$ in the multilinear statistical approach. This suggests that the use of the nonlinear fitting approach reduces the uncertainty by 36$39 \%$ compared to the multilinear regression.

\section{2 $\quad \mathrm{RF}_{\mathrm{aci}}$ and uncertainties}

Aerosols and clouds vary substantially as a function of time in all regions; thus, it is interesting to analyse aerosol-cloud interactions as a function of season. Figure 4 shows the seasonal variability of 6-year averaged radiative forcing by aerosol-cloud interaction for the three regions as defined above. The maximum anthropogenic $\mathrm{RF}_{\mathrm{aci}}$ is found over oceanic regions (AS: $-0.15 \mathrm{~W} \mathrm{~m}^{-2}$; $\mathrm{BOB}:-0.16 \mathrm{~W} \mathrm{~m}^{-2}$ ) instead of regions over land (CI: $-0.12 \mathrm{~W} \mathrm{~m}^{-2}$ ) with high anthropogenic emissions. This is because maritime clouds are more susceptible to changes in the concentration of anthropogenic aerosols (Quaas et al., 2008). In contrast, the natural $\mathrm{RF}_{\mathrm{aci}}$ is generally stronger over land $\left(-0.15 \mathrm{~W} \mathrm{~m}^{-2}\right)$ than over oceanic regions (AS: $-0.098 \mathrm{~W} \mathrm{~m}^{-2}$; BOB: $-0.07 \mathrm{~W} \mathrm{~m}^{-2}$ ). It is seen that the anthropogenic $\mathrm{RF}_{\mathrm{aci}}$ is strongest during winter over $\mathrm{AS}$ and $\mathrm{BOB}$, with values near -0.19 and $-0.22 \mathrm{~W} \mathrm{~m}^{-2}$, whereas it is strong $\left(-0.2 \mathrm{~W} \mathrm{~m}^{-2}\right)$ during the pre-monsoon over CI (land). The dominance of natural aerosols in the pre-monsoon results in a large natural $\mathrm{RF}_{\mathrm{aci}}$ both over land $\left(-0.15 \mathrm{~W} \mathrm{~m}^{-2}\right)$ and ocean $(-0.098$ and $-0.07 \mathrm{~W} \mathrm{~m}^{-2}$ ). 

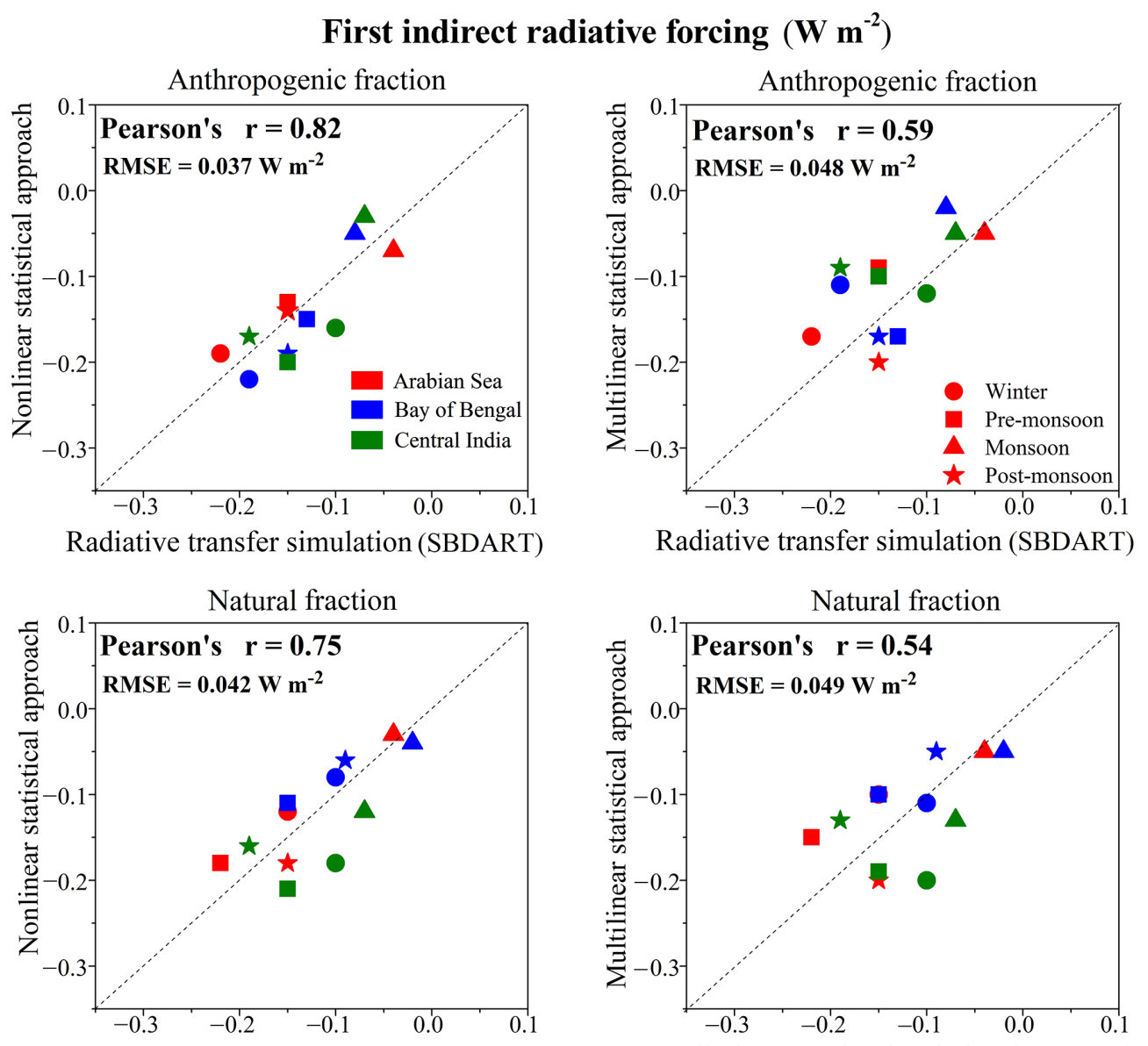

Radiative transfer simulation (SBDART)

Radiative transfer simulation (SBDART)

Figure 3. Comparison between satellite-based $\mathrm{RF}_{\mathrm{aci}}$ using both statistical fits and the one simulated by the SBDART model for all three regions and for all seasons. The different colours indicate the regions, whereas the different symbols indicate the different seasons. Note that the fit is separately performed for each season and each region.

A direct comparison of the satellite to simulations-based $\mathrm{RF}_{\mathrm{aci}}$ shows a good correlation. However, both satelliteestimated and -simulated $\mathrm{RF}_{\mathrm{aci}}$ are subject to errors, and it is useful to compute the associated uncertainties in the above results due to various parameters. Uncertainty involves the ones due to satellite retrievals of AOD which can be highly biased in the vicinity of cloud due to swelling (Koren et al., 2007) and also due to 3-D effects (Wen et al., 2007). Since both biases may be particularly high for thick clouds, our estimate of the $\mathrm{RF}_{\mathrm{aci}}$ could be still be overestimated. The uncertainty in MODIS retrievals of AOD from validation studies (Levy et al., 2007) was quantified at $0.03+0.05 \tau_{\mathrm{a}}$ over ocean and $0.05+0.15 \tau_{\mathrm{a}}$ over land. However, since we use the MODIS-OMI algorithm (Kim et al., 2007) to estimate the anthropogenic and natural fraction of AOD, uncertainty in this is given as $1 \sigma$ standard deviations as per Table S2. From satellite intercomparison, the uncertainty in radiative flux retrievals by CERES is estimated at $5 \%$ (Loeb, 2004), and uncertainty in cloud optical depth is $21 \%$ (Minnis et al., 2004). The uncertainties due to the sensitivity of $N_{\mathrm{d}}$ to a relative change in AOD $\left(d \ln N_{\mathrm{d}} / d \ln \tau_{\mathrm{a}}\right)$ contribute most to the total uncertainty. For $N_{\mathrm{d}}$ sensitivities to changes in AOD, standard deviations are derived from minimum and maximum values obtained for each season. Following the study by Bellouin et al. (2013), the standard deviations are derived from minimum and maximum values by defining a 4-sigma interval, which covers the large range of sensitivities and spatio-temporal variabilities. To define the standard deviations in $\mathrm{RF}_{\text {aci }}$ due to variation in $d \ln N_{\mathrm{d}} / d \ln \tau_{\mathrm{a}}, \mathrm{RF}_{\mathrm{aci}}$ is recomputed using those standard deviations of $N_{\mathrm{d}}$ sensitivities to changes in AOD. Table 2 shows the seasonal and regional sensitivities of $d \ln N_{\mathrm{d}} / d \ln \tau_{\mathrm{a}}$ along with their statistical standard deviation, which is computed from the minimum and maximum values for each season. The associated range in $\mathrm{RF}_{\mathrm{aci}}$ for both the anthropogenic and the natural fraction of AOD is also shown in Table 2, where the standard deviation of $\mathrm{RF}_{\mathrm{aci}}$ shows the variation due to change in $d \ln N_{\mathrm{d}} / d \ln \tau_{\mathrm{a}}$, which finally contributes to the total uncertainty. In addition to this, the computed $\mathrm{RF}_{\mathrm{aci}}$ in this study is associated with the statistical fitting approach as described in 

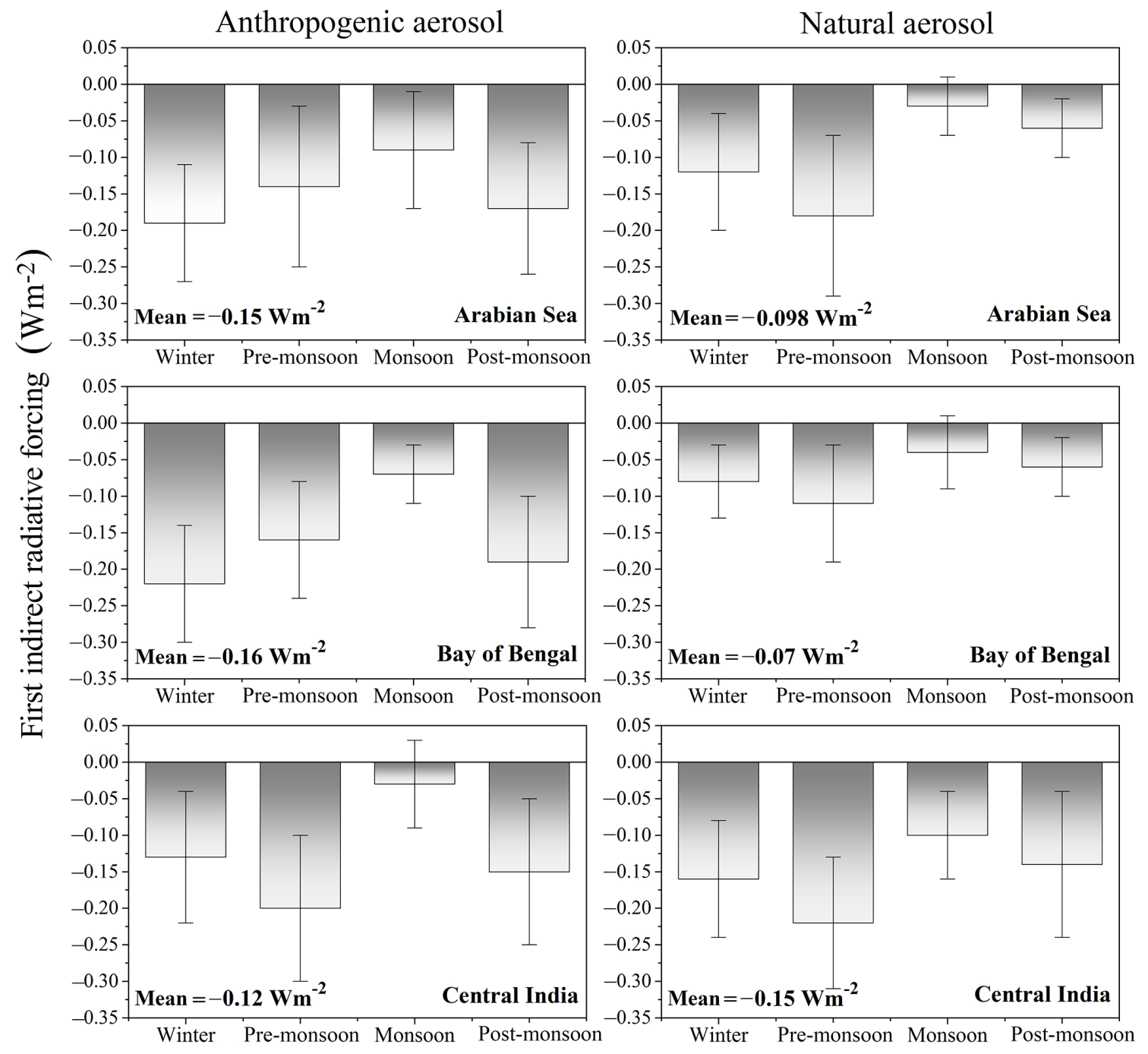

Figure 4. Seasonal variability of 6-year averaged $\mathrm{RF}_{\mathrm{aci}}$ obtained using the nonlinear fit for all three regions for both anthropogenic and natural aerosols along with mean values.

Sect. 3. As mentioned earlier, two different statistical fitting methods are used to obtain the regression coefficients for the estimate of $\mathrm{RF}_{\mathrm{aci}}$. In the present study, except for the statistical fitting method, all the variables and methodologies are the same for both statistical approaches. Therefore, we used the relative difference between the RT-simulated and statistically computed $\mathrm{RF}_{\mathrm{aci}}$ as an uncertainty due to the choice of the statistical fitting approach for both the statistical fitting methods. As shown in Sect. 4.1, the mean relative differences for the nonlinear and multilinear approaches are 0.021 and $0.033 \mathrm{~W} \mathrm{~m}^{-2}$, respectively, in $\mathrm{RF}_{\text {aci }}$ for anthropogenic fraction, whereas for the $\mathrm{RF}_{\mathrm{aci}}$ of the natural fraction of AOD, these are 0.032 and $0.053 \mathrm{~W} \mathrm{~m}^{-2}$ for nonlinear and multilinear statistical approaches, respectively. Table 3 lists the uncertainty due to different parameters involved in the satellitebased estimate of $\mathrm{RF}_{\mathrm{aci}}$. We quantify the relative error as the square root of the sum of the squared relative errors for all in- dividual contributions. This yields an influence of these relative uncertainties in the input quantities on the computed $\mathrm{RF}_{\text {aci }}$ of $\sim \pm 0.08 \mathrm{~W} \mathrm{~m}^{-2}$. It should be noted that we refer here to the published quantifiable uncertainties in the satellite retrievals. The limitation involved in this approach or the uncertainties in the satellite retrievals contribute to the overall uncertainty, which is difficult to quantify.

In addition to above error budget, there are uncertainties involved in the RT-simulated $\mathrm{RF}_{\mathrm{aci}}$ due to various parameters, as shown above. In this regard, the surface albedo plays a major role in the simulation of $\mathrm{RF}_{\mathrm{aci}}$. In the standard approach, we have considered a surface albedo value 0.15 for land and the predefined option for the ocean surface albedo is used for the oceanic regions in the present study. To quantify the uncertainties involved due to assumptions about the surface albedo, we have simulated $\mathrm{RF}_{\mathrm{aci}}$ with different plausible surface albedo values and computed statistics as shown 
Table 2. Seasonal and regional sensitivities $d \ln N_{\mathrm{d}} / d \ln \tau_{\mathrm{a}}$ of cloud droplet number concentration $N_{\mathrm{d}}$ to the changes in aerosol optical depth used in this study. The given standard deviation is derived from minimum and maximum values for a particular season. The associated range in $\mathrm{RF}_{\mathrm{aci}}$ is also estimated where the standard deviation of $\mathrm{RF}_{\mathrm{aci}}$ shows the variation due to change in $d$ ln $N_{d} / d$ ln $\tau_{\mathrm{a}}$. Variation due to change in $d \ln N_{d} / d \ln \tau_{\mathrm{a}}$.

\begin{tabular}{llrrrr}
\hline & Region & Winter & Pre-monsoon & Monsoon & Post-monsoon \\
\hline & AS & $0.384 \pm 0.146$ & $0.408 \pm 0.189$ & $0.272 \pm 0.131$ & $0.18 \pm 0.102$ \\
$\frac{d \ln N_{\mathrm{d}}}{d \ln \tau}$ & $\mathrm{BOB}$ & $0.314 \pm 0.136$ & $0.414 \pm 0.15$ & $0.194 \pm 0.104$ & $0.148 \pm 0.088$ \\
& $\mathrm{CI}$ & $0.214 \pm 0.107$ & $0.178 \pm 0.105$ & $0.107 \pm 0.069$ & $0.122 \pm 0.071$ \\
\hline $\mathrm{Rf}_{\text {aci }}$ for & $\mathrm{AS}$ & $-0.19 \pm 0.036$ & $-0.14 \pm 0.056$ & $-0.08 \pm 0.036$ & $-0.16 \pm 0.036$ \\
anthropogenic & $\mathrm{BOB}$ & $-0.22 \pm 0.062$ & $-0.16 \pm 0.036$ & $-0.07 \pm 0.02$ & $-0.2 \pm 0.036$ \\
fraction & $\mathrm{CI}$ & $-0.13 \pm 0.02$ & $-0.2 \pm 0.036$ & $-0.05 \pm 0.034$ & $-0.16 \pm 0.036$ \\
\hline $\mathrm{Rf}_{\text {aci }}$ for & $\mathrm{AS}$ & $-0.12 \pm 0.036$ & $-0.18 \pm 0.036$ & $-0.03 \pm 0.04$ & $-0.06 \pm 0.036$ \\
natural & $\mathrm{BOB}$ & $-0.08 \pm 0.026$ & $-0.11 \pm 0.026$ & $-0.04 \pm 0.039$ & $-0.06 \pm 0.017$ \\
fraction & $\mathrm{CI}$ & $-0.16 \pm 0.027$ & $-0.22 \pm 0.055$ & $-0.1 \pm 0.027$ & $-0.14 \pm 0.036$ \\
\hline
\end{tabular}

Table 3. Lists the sources of uncertainties and their values involved in the satellite-based estimate of $\mathrm{RF}_{\mathrm{aci}}$ in the present study.

\begin{tabular}{|c|c|}
\hline Source of uncertainty & Values \\
\hline Total AOD & $\begin{array}{l}0.03 \pm 0.05 . \tau_{\mathrm{a}} \\
\text { over ocean } \\
0.05 \pm 0.05 . \tau_{\mathrm{a}} \\
\text { over land }\end{array}$ \\
\hline $\begin{array}{l}\text { MODIS-OMI algorithm } \\
\text { (for the estimate of } \\
\text { anthropogenic and natural } \\
\text { fraction of aerosol) }\end{array}$ & $\begin{array}{l}1 \sigma \text { standard deviation } \\
\text { as per } \\
\text { Table S2 }\end{array}$ \\
\hline Flux retrieval from CERES & $5 \%$ \\
\hline $\begin{array}{l}\text { Cloud optical depth retrieval } \\
\text { from CERES }\end{array}$ & $21 \%$ \\
\hline $\begin{array}{l}\text { Cloud droplet number } \\
\text { concentration }\end{array}$ & see Table 2 \\
\hline Statistical fitting approach & $\begin{array}{l}0.021 \mathrm{~W} \mathrm{~m}^{-2} \text { in } \\
\text { nonlinear for } \\
\text { anthropogenic fraction; } \\
0.032 \mathrm{~W} \mathrm{~m}^{-2} \text { in } \\
\text { nonlinear for natural } \\
\text { fraction; } \\
0.033 \mathrm{~W} \mathrm{~m}^{-2} \text { in } \\
\text { multilinear for } \\
\text { anthropogenic fraction; } \\
0.053 \mathrm{~W} \mathrm{~m}^{-2} \text { in } \\
\text { multilinear for natural } \\
\text { fraction }\end{array}$ \\
\hline
\end{tabular}

in Table S3a and $\mathrm{b}$. The statistics show that the considered values of surface albedo are suitably representative of the study regions. In addition, RT simulation have their own limitations and uncertainties, e.g. inherent code accuracy, over- estimate in calculated RF due to plane-parallel bias and 3-D radiative transfer effect. It would be useful to explore these issues in the future. However, in the present study, RT simulation is used to evaluate the results computed with satellitebased measurements. There is scope to improve the present study with the upcoming data set retrieved from spaceborne active remote-sensing instruments, with the improved satellite products and with the new statistical relationship.

\section{Conclusions}

In this study, we employed a new nonlinear statistical fitting approach to develop the statistical relationship. A satellitebased algorithm is used to quantify the anthropogenic and natural fraction of aerosol optical depth for the computation of $\mathrm{RF}_{\mathrm{aci}}$ from satellite retrievals. In order to verify $\alpha$ and $\mathrm{RF}_{\mathrm{aci}}$ estimates using the new statistical approach (nonlinear) along with the previous statistical approach (multilinear fit), these are compared with the results obtained from radiative transfer simulations. The results show a better agreement between model-based estimates and the one estimated using the nonlinear approach compared to the multilinear approach. The nonlinear approach relatively increases by $21-23 \%$ the correlation coefficient and reduces the RMSE by 0.007 to $0.011 \mathrm{~W} \mathrm{~m}^{-2}$ compared to multilinear approach. The nonlinear fitting approach reduces the relative difference by 36 $39 \%$ compared to the multilinear regression method. The $\mathrm{RF}_{\mathrm{aci}}$ is found to be consistent with the value found by the statistical relationship between aerosol and cloud properties from MODIS and CERES, respectively, and radiative transfer calculations. Further studies using the data retrieved from advanced instruments, e.g. lidar and radar, may be useful to test the assumption made in the present study concerning the proxy of the aerosol column and the overestimation of AOD over land and to deal with multi-layer clouds. 
Data availability. The data used in the present study are freely available online as detailed in the acknowledgements or provided in the Supplement.

\section{The Supplement related to this article is available online at doi:10.5194/acp-17-3687-2017-supplement.}

Competing interests. The authors declare that they have no conflict of interest.

Acknowledgements. The authors gratefully acknowledge the constant encouragement received from the Director, SAC, for carrying out the present research work. Valuable suggestions received from the Deputy Director, EPSA, and the Head, CVD, are also gratefully acknowledged. CERES SSF data were obtained from the NASA Langley Research Centre Atmospheric Sciences Data Centre (ASDC), and MODIS data used in this study were acquired as part of NASA's Earth Science Enterprise. The MODIS Science Teams developed the algorithms for the AOD retrievals. The data were processed by the MODIS Adaptive Processing System for the AOD retrievals. The data were processed by the MODIS Adaptive Processing System and the Goddard Distributed Active Archive (DAAC). The Dutch-Finnish-built OMI instrument is part of the NASA EOS Aura satellite payload. The OMI project is managed by NIVR and KNMI in the Netherlands. The OMI data were also obtained from the DAAC. Reanalysis data are from the European Centre for Medium-Range Weather Forecasts. The authors would like to thank the data distribution centres for their support, Markand Oza for helpful discussion, and their families for their continuous motivation. Johannes Quaas acknowledges funding by the European Research Council (GA no. 306284). The authors are grateful to three anonymous reviewers for constructive and useful comments. We acknowledge financial support from the German Research Foundation (DFG) and Universität Leipzig within the program of Open Access Publishing.

Edited by: A. Sorooshian

Reviewed by: three anonymous referees

\section{References}

Bellouin, N., Jones, A., Haywood, J., and Christopher, S. A.: Updated estimate of aerosol direct Radiative forcing from satellite observations and comparison against the centre climate model, J. Geophys. Res. Atmos., 113, D10205, doi:10.1029/2007JD009385, 2008.

Bellouin, N., Quaas, J., Morcrette, J. J., and Boucher, O.: Estimates of aerosol radiative forcing from the MACC re-analysis, Atmos. Chem. Phys., 13, 2045-2062, doi:10.5194/acp-13-20452013, 2013.

Bennartz, R.: Global assessment of marine boundary layer cloud droplet number concentration from satellite, J. Geophys. Res., 112, D02201, doi:10.1029/2006jd007547, 2007.

Bennartz, R. and Rausch, J.: Global and regional estimates of warm cloud droplet number concentration based on 13 years of AQUA-MODIS observations, Atmos. Chem. Phys. Discuss., doi:10.5194/acp-2016-1130, in review, 2017.

Brenguier, J.-L., Pawlowska, H., Schüller, L., Preusker, R., Fischer, J., and Fouquart, Y.: Radiative Properties of Boundary Layer Clouds: Droplet Effective Radius versus Number Concentration, J. Atmos. Sci., 57, 803-821, 2000.

Boucher, O., Randall, D., Artaxo, P., Bretherton, C., Feingold, G., Forster, P., Kerminen, V.-M., Kondo, Y., Liao, H., Lohmann, U., Rasch, P., Satheesh, S. K., Sherwood, S., Stevens, B., and Zhang, X. Y.: Clouds and Aerosols, in: Climate Change 2013: The Physical Science Basis. Contribution of Working Group I to the Fifth Assessment Report of the Intergovernmental Panel on Climate Change, edited by: Stocker, T. F., Qin, D., Plattner, G. K., Tignor, M., Allen, S. K., Boschung, J., Nauels, A., Xia, Y., Bex, V., and Midgley, P. M., Cambridge University Press, Cambridge, United Kingdom and New York, NY, USA, 571-658, 2013.

Cherian, R., Venkataraman, C., Quaas, J., and Ramachandran, S.: GCM simulations of anthropgenic aerosol-induced cahnges in aerosol extinction, atmiospheric heating and precepitaion over India, J. Geophys. Res.-Atmos, 11, 2938-2955, doi:10.1002/jgrd.50298, 2013.

Chin, M., Rood, R. B., Lin, S. J., Muller, J. F., and Thompson, A. M.: Atmospheric sulfur cycle simulated in the global model GOCART: model description and global properties, J. Geophys. Res., 105, 24671-24687, 2000.

Das, S., Dey, S., and Dash, S. K.: Direct radiative effects of anthropogenic aerosols on Indian summer monsoon circulation, Theor Appl. Climatol., 124, 629-639, doi:10.1007/s00704-015-1444-8, 2015.

Di Girolamo, L. D., Bond, T. C., Bramer, D., Diner, D. J., Fettinger, F., Kahn, R. A., Martonchik, J. V., Ramana, M. V., Ramanathan, V., and Rasch, P. J.: Analysis of Multi-angle Imaging Spectroradiometer (MISR) aerosol optical depths over greater India during winter 2001, Geophys. Res. Lett., 31, L23115, doi:10.1029/2004GL021273, 2004.

Feingold, G., Remer, L. A., Ramaprasad, J., and Kaufman, Y. J.: Analysis of smoke impact on clouds in Brazilian biomass burning regions: An extension of Twomey's approach, J. Geophys. Res., 106, 22907-22922, 2001.

Feingold, G., Eberhard, W. L., Veron, D. E., and Previdi, M.: First measurements of the Twomey indirect effect using ground-based remote sensors, Geophys. Res. Lett., 30, 1287, doi:10.1029/2002GL016633, 2003.

Huber, M. and Knutti, R.: Anthropogenic and natural warming inferred from changes in Earth's energy balance, Nat. Geosci., 5, 31-36, doi:10.1038/ngeo1327, 2011.

IPCC: Intergovernmental Panel on Climate Change: Climate Change 2007: The Physical Scientific Basis, edited by: Solomon, S., Qin, D., Manning, M., Chen, Z., Marquis, M., Averyt, K. B., Tignor, M., and Miller, H. L., Cambridge Univ. Press, New York, 2007.

Kim, J., Lee, J., Lee, H. C., Higurashi, A., Takemura, T., and Song, C. H.: Consistency of the aerosol type classification from satellite remote sensing during the Atmospheric Brown Cloud-East Asia Regional Experiment campaign, J. Geophys. Res.-Atmos., 112, D22S33, doi:10.1029/2006JD008201, 2007.

Koren, I., Remer, L. A., Kaufman, Y. J., Rudich, Y., and Martins, J. V.: On the twilight zone between clouds and aerosols, Geophys. Res. Lett., 34, L08805, doi:10.1029/2007GL029253, 2007. 
Levelt, P. F., Van Den Oord, G. H. J., Dobber, M. R., Mälkki, A., Visser, H., De Vries, J., and Saari, H.: The ozone monitoring instrument, IEEE T. Geosci. Remote, 44, 1093-1100, doi:10.1109/TGRS.2006.872333, 2006.

Levenberg, K.: A Method for the Solution of Certain Non-Linear Problems in Least Squares, Q. Appl. Math., 2, 164-168, 1944.

Levy, R. C., Remer, L. A., Mattoo, S., Vermote, E. F., and Kaufman, Y. J.: Second-generation operational algorithm: Retrieval of aerosol properties over land from inversion of Moderate Resolution Imaging Spectroradiometer spectral reflectance, J. Geophys. Res.-Atmos., 112, D13211, doi:10.1029/2006JD007811, 2007.

Liu, J., Mauzerall, D. L., and Horowitz, L. W.: Evaluating intercontinental transport of fine aerosols: Global health impact, Atmos. Environ., 43, 4339-4347, 2009.

Loeb, N.: Angular models: Instantaneous and ensemble accuracy, in: 1st CERES-II Science Team Meeting Proceedings, NCAR, Boulder, Colorado, USA, 2004.

Loeb, N. G., Wielicki, B. A., Su, W., Loukachine, K., Sun, W., Wong, T., Priestley, K. J., Matthews, G., Miller, W. F., and Davies, R.: Multi-instrument comparison of top-of-atmosphere reflected solar radiation, J. Clim., 20, 575-591, 2007.

Ma, X., Fangqun, Yu., and Quaas, J.: Reassessment of satellitebased estimate of aerosol cloud forcing, J. Geophys. Res.Atmos., 119, 10394-10409, doi:10.1002/2014JD021670, 2014.

McComiskey, A., Feingold, G., Frisch, A. S., Turner, D. D., Miller, M. A., Chiu, J. C., Min, Q., and Ogren, J. A.: An assessment of aerosol-cloud interactions in marine stratus clouds based on surface remote sensing, J. Geophys. Res., 114, D09203, doi:10.1029/2008JD011006, 2009.

McComiskey, A. and Feingold, G.: The scale problem in quantifying aerosol indirect effects, Atmos. Chem. Phys., 12, 1031-1049, doi:10.5194/acp-12-1031-2012, 2012.

Minnis, P., Young, D. F., Sun-Mack, S., Heck, P. W., Doelling, D. R., and Trepte, Q. Z.: CERES cloud property retrievals from imagers on TRMM, Terra, and Aqua, in: Proc. SPIE 10th International Symposium on Remote Sensing: Conference on Remote Sensing of Clouds and the Atmosphere VII, vol. 5235, Barcelona, Spain, 37-48, 2003.

Minnis, P., Young, D. F., Sun-Mack, S., Trepte, Q., Doelling, D. R., Spangenberg, D. A., and Heck, P. W.: Ceres cloud products, in 1st CERES-II Science Team Meeting Proceedings, NCAR, Boulder, Colorado, 2004.

Moorthy, K. K., Babu, S. S., Manoj, M. R., and Satheesh, S. K.: Buildup of aerosols over the Indian region, Geophys. Res. Lett., 40, 1011-1014, doi:10.1002/grl.50165, 2013.

Moorthy, K. K.., Satheesh, S. K., Sarin, M. M., and Panday, A. K.: South Asian aerosols in perspective: Preface to the special issue, Atmos. Environ., 125, 307-311, doi:10.1016/j.atmosenv.2015.10.073, 2015.

Parkinson, C. L.: Aqua: An earth-observing satellite mission to examine water and other climate variables, IEEE T. Geosci. Remote, 41, 173-183, doi:10.1109/TGRS.2002.808319, 2003.

Penner, J. E., Xu, L., and Wang, M.: Satellite methods underestimate indirect climate forcing by aerosols, P. Natl. Acad. Sci. USA, 108, 13404-13408, doi:10.1073/pnas.1018526108, 2011.

Penner, J. E., Zhou, C., and Xu, L.: Consistent estimates from satellites and models for the first aerosol indirect forcing, Geophys. Res. Lett., 39, LL13810, doi:10.1029/2012GL051870, 2012.
Quaas, J., Boucher, O., and Lohmann, U.: Constraining the total aerosol indirect effect in the LMDZ and ECHAM4 GCMs using MODIS satellite data, Atmos. Chem. Phys., 6, 947-955, doi:10.5194/acp-6-947-2006, 2006.

Quaas, J., Boucher, O., Bellouin, N., and Kinne, S.: Satellite-based estimate of the direct and indirect aerosol climate forcing, J. Geophys. Res.-Atmos., 113, 1-9, doi:10.1029/2007JD008962, 2008.

Quaas, J., Ming, Y., Menon, S., Takemura, T., Wang, M., Penner, J. E., Gettelman, A., Lohmann, U., Bellouin, N., Boucher, O., Sayer, A. M., Thomas, G. E., McComiskey, A., Feingold, G., Hoose, C., Kristjánsson, J. E., Liu, X., Balkanski, Y., Donner, L. J., Ginoux, P. A., Stier, P., Grandey, B., Feichter, J., Sednev, I., Bauer, S. E., Koch, D., Grainger, R. G., Kirkevåg, A., Iversen, T., Seland, Ø., Easter, R., Ghan, S. J., Rasch, P. J., Morrison, H., Lamarque, J.-F., Iacono, M. J., Kinne, S., and Schulz, M.: Aerosol indirect effects - general circulation model intercomparison and evaluation with satellite data, Atmos. Chem. Phys., 9, 8697-8717, doi:10.5194/acp-9-8697-2009, 2009.

Quaas, J., Boucher, O., Bellouin, N., and Kinne, S.: Which of satellite- or model-based estimates is closer to reality for aerosol indirect forcing?, P. Natl. Acad. Sci. USA, 108, E1099, doi:10.1073/pnas.1114634108, 2011.

Rausch, J., Heidinger, A., and Bennartz, R.: Regional assessment of microphysical properties of marine boundary layer cloud using the PATMOS-x dataset, J. Geophys. Res.-Atmos., 115, D23212, doi:10.1029/2010jd014468, 2010.

Remer, L. A., Kaufman, Y. J., Tanré, D., Mattoo, S., Chu, D. A., Martins, J. V., Li, R-R., Ichoku, C., Levy, R. C., Kleidman, R. G., Eck, T. F., Vermote, E., and Holben, B. N.: The MODIS Aerosol Algorithm, Products, and Validation, J. Atmos. Sci., 62, 947-973, doi:10.1175/JAS3385.1, 2005.

Ricchiazzi, P., Yang, S., Gautier, C., and Sowle, D.: SBDART: A Research and Teaching Software Tool for Plane-Parallel Radiative Transfer in the Earth's Atmosphere, B. Am. Meteorol. Soc., 79, 2101-2114, 1998.

Schoeberl, M. R., Douglass, A. R., Hilsenrath, E., Bhartia, P. K., Beer, R., Waters, J. W., et al.: Overview of the EOS aura mission, IEEE T. Geosci. Remote, 44, 1066-1072, doi:10.1109/TGRS.2005.861950, 2006.

Schüller, L., Bennartz, R., Fischer, J., and Brenguier, J.-L.: An algorithm for the retrieval of droplet number concentration and geometrical thickness of stratiform marine boundary layer clouds applied to MODIS radiometric observations, J. Appl. Meteorol., 44, 28-38, 2005.

Stamnes, K., Tsay, S. C., Wiscombe, W., and Jayaweera, K.: Numerically stable algorithm for discrete-ordinate-method radiative transfer in multiple scattering and emitting layered media, Appl. Optics, 27, 2502-2509, doi:10.1364/AO.27.002502, 1988.

Tiwari, S., Mishra, A. K., and Singh, A. K.: Aerosol climatology over the Bay of Bengal and Arabian Sea inferred from sapceborne radiometers and lidar observations, Aerosol Air Qual. Res., 16, 2855-2868, doi:10.4209/aaqr.2015.06.0406, 2015.

Torres, O., Bhartia, P. K., Herman, J. R., Ahmad, Z., and Gleason, J.: Derivation of aerosol properties from satellite measurements of backscattered ultraviolet radiation: Theoretical basis, J. Geophys. Res.-Atmos., 103, 17099-17110, doi:10.1029/98JD00900, 1998.

Transtrum, M. K. and Sethna, J. P.: Improvements to the LevenbergMarquardt algorithm for nonlinear least-squares minimization, J. Comput. Phys., 2012. 
Transtrum, M. K., Machta, B. B., and Sethna, J. P.: Why are nonlinear ?ts to data so challenging?, Phys. Rev. Lett., 104, 060201, doi:10.1103/PhysRevLett.104.060201, 2010.

Twomey, S.: The Influence of Pollution on the Shortwave Albedo of Clouds, J. Atmos. Sci., 34, 1149-1152, doi:10.1175/15200469(1977)034<1149:TIOPOT>2.0.CO;2, 1977.
Wen, G., Marshak, A., Cahalan, R. F., Remer, L. A., and Kleidman, R. G.: 3-D aerosol-cloud radiative interaction observed in collocated MODIS and ASTER images of cumulus cloud fields, J. Geophys. Res.-Atmos., 112, D13204, doi:10.1029/2006JD008267, 2007.

Wielicki, B. A., Barkstrom, B. R., Harrison, E. F., Lee, R. B., Smith, G. L., and Cooper, J. E.: Clouds and the Earth's Radiant Energy System (CERES): An Earth Observing System Experiment, B. Am. Meteorol. Soc., 77, 853-868, 1996. 